\title{
A EDUCAÇÃO AMBIENTAL COMO INSTRUMENTO NA ADMINISTRAÇÃO DOS PROBLEMAS DO LIXO ELETRÔNICO: UMA PROPOSTA
}

\author{
Luiz Fernando Whitaker Kitajima ${ }^{1}$ \\ Graziela Ferreira Guarda ${ }^{2}$ \\ Regina Célia Rebouças Dalston ${ }^{3}$ \\ Beatriz Barcelos ${ }^{4}$. \\ George Henrique de Moura Cunha ${ }^{5}$ \\ Edilson Ferneda ${ }^{6}$
}

Resumo: O lixo eletrônico é um resíduo sólido com milhões de toneladas produzidas anualmente, e que causa sérios problemas ambientais, legais e sociais devido a sua composição. A solução deste pode ser pela reciclagem, reuso e descarte final adequado, que podem ser também alcançadas mediante educação da sociedade, de acordo com princípios definidos em conferências internacionais e pela legislação brasileira. Essa educação pode ser feita no ambiente educacional formal e não-formal. Exposições de fotografias, exemplos de lixo eletrônico e de objetos feitos a partir dos mesmos, questionários sobre a presença do lixo eletrônico na rotina diária, simulações de tratamento químico do lixo eletrônico são exemplos destas atividades.

Palavras-chave: Lixo Eletrônico, Educação Ambiental, Reciclagem, Reuso, Logística Reversa.

${ }^{1}$ Professor do Centro Universitário do DF (UDF) e Faculdade da Confederação Nacional da Agricultura (FCNA). E-mail: luizfwk@gmail.com

2 Professora da Universidade Católica de Brasília (UCB). E-mail: grazielafguarda@gmail.com

3 Professora da Universidade Católica de Brasília (UCB). E-mail: rdalston@gmail.com

${ }_{4}^{4}$ Professora da Universidade Católica de Brasília (UCB). E-mail:

beatriz.rodrigues.barcelos@gmail.com

${ }^{5}$ Pesquisador da Universidade de Brasília - UNB. E-mail: georgehmc@outlook.com

${ }^{6}$ Professor do curso da Ciência da Computação da Universidade Católica de Brasília/ UCB,

Brasília, DF. E-mail: eferneda@pos.ucb.br

Revbea, São Paulo, V. 14, № 3: 122-137, 2019. 


\section{Introdução}

O crescimento da população, a urbanização e o desenvolvimento tecnológico, se por um lado geraram uma série de avanços às condições de habitação, saúde, emprego e lazer a um número maior de pessoas, por outro lado criou grandes pressões sobre os recursos e serviços naturais e sobre a manutenção dos ecossistemas. Tais pressões, além de significar os riscos de redução da oferta de bens naturais necessários à saúde humana e dos demais organismos, podem ainda significar riscos à própria existência dos mesmos, através da deterioração das condições físicas, químicas e biológicas naturais (MOTA, 2006).

A poluição atmosférica, das águas e do solo já são responsáveis por milhares de casos de doenças e de mortes, especialmente entre recémnascidos, enquanto a falta de água doce potável já é uma realidade em vários países do mundo. Há ainda o círculo vicioso onde para abastecer as necessidades humanas, promove-se uma deterioração ainda maior do ambiente, gerando mais problemas em longo prazo e criando mais problemas para a própria existência humana (MOTA, 2006).

A necessidade de se procurar as respostas e soluções para estes problemas não se restringem apenas em medidas para se encontrar métodos produtivos mais eficientes e que promovam menor emissão de poluentes ao ambiente ou não uso mais eficiente dos recursos, ou ao tratamento dos resíduos gerados. Também inclui a conscientização das pessoas, em especial dentro do ambiente de ensino, de forma a permitir que estas atuem de forma a promover atitudes e comportamentos que levem a sustentabilidade.

O objetivo deste artigo é, portanto, tratar da aplicação dos princípios básicos da Educação Ambiental no controle e redução do chamado lixo eletrônico ou e-lixo, com propostas de atividades e com base em pesquisas feitas pelo grupo de pesquisa no qual os autores pertencem.

\section{O problema do lixo eletrônico}

O lixo eletrônico, ou e-lixo, é o termo para os equipamentos elétricos e eletrônicos, completos ou suas partes, que são descartadas pelos usuários sem intenção de reuso (BALDÉ et al., 2015, 2017). Estes equipamentos são agrupados em:

a)Equipamentos de refrigeração/aquecimento. Exemplo: geladeiras, freezers;

b)Monitores e telas de televisão;

c) Lâmpadas, especialmente fluorescentes e LED;

d)Equipamentos de grande porte. Exemplos: copiadoras, fogão elétrico, painéis fotovoltaicos;

e)Equipamentos de pequeno porte. Exemplos: fornos de microondas, secadoras de cabelo, rádios; e, 
f) Equipamentos de TI (Tecnologia da Informação) como telefones celulares.

Este tipo de resíduo tem representado um problema ambiental crescente devido a dois fatores básicos e relacionados, que são o volume crescente do resíduo produzido e a sua constituição química.

O crescimento do volume de e-lixo produzido tem-se tornado muito rápido. Uma medida disto é que no ano de 2010 foram produzidos, em escala global, cerca de 33,8 milhões de toneladas de e-lixo,em 2016 o valor total atingiu 44,7 milhões de toneladas. Para 2018 é previsto um total de 50 milhões de toneladas produzidas, o que implica em cerca de 6,7 quilogramas de lixo eletrônico produzidos per capita em 2018, podendo chegar a 52 milhões de toneladas em 2021 (BALDÉ et al., 2015, 2017).

Neste contexto, segundo dados de 2016, as maiores contribuições para a produção de e-lixo foram a Ásia (18,2 milhões de toneladas), seguidas pelas Américas e Europa (respectivamente, 11,3 e 12,3 milhões de toneladas). 0 Brasil, em 2016, produziu 1,5 milhões de toneladas de e-lixo (BALDÉ et al., 2017).

Os problemas ambientais advindos deste tipo de resíduo são provocados pelo seu descarte inadequado, em muitos casos em lixões ou aterros controlados, a céu aberto, expostos à ação atmosférica, que promove a deterioração dos componentes e liberação dos seus elementos constituintes para o ambiente, com graves consequências. Isso se deve ao fato de que esses componentes são, em muitos casos, metais pesados ou compostos sintéticos como plásticos e outros, cuja queima libera toxinas na atmosfera (FERREIRA; FERREIRA, 2008; BALDÉ et al., 2017).

Pode-se citar, entre os componentes com potencial tóxico presentes no e-lixo, o chumbo, cobre, zinco, mercúrio e cádmio, enquanto os plásticos PVC, quando queimados, geram fumaça tóxica e os retardantes de fogo a base de bromo (BRT) que também apresentam toxidade (FERREIRA; FERREIRA, 2008). Ocorre destarte a poluição do ar, solo e águas, e considerando que apenas $20 \%$ deste resíduo são reciclados, o volume que sofre disposição final apresenta um grande potencial de impactos ambientais em larga escala (BALDÉ et al., 2017).

No caso do Brasil, em 2015 o destino de descarte dos resíduos sólidos urbanos, que inclui o e-lixo, foi de $58,7 \%$ para aterros sanitários, $24,1 \%$ para aterros controlados e $17,2 \%$ nos lixões. Isso significa, em outros números, que em 2015 mais de 80.000 toneladas/dia de resíduos sólidos tinham um destino final que eram parcialmente ou totalmente inadequados em termos ambientais (ABRELPE, 2015).

Outro problema associado ao e-lixo é o comércio e reciclagem ilegais e 
substâncias que são valiosas, surgiu um comércio ilegal de lixo eletrônico onde este resíduo é retirado de forma clandestina de países na Europa, Ásia e América do Norte e levado para comunidades de baixa renda, especialmente na África e também na Ásia, onde ocorre trabalho em condições precárias, muitas vezes com o uso de trabalho infantil, onde ocorre a reciclagem de forma inadequada e que causa ainda mais contaminação ambiental (BISSCHOP 2012).

\section{A Educação Ambiental e desenvolvimento sustentável}

A Educação Ambiental e o desenvolvimento sustentável têm origens, como conceitos formalmente definidos e integrados, e não como ideias fragmentadas, somente a partir da década de 1970 (BARBIERI; SILVA, 2011).

$\mathrm{Na}$ Conferência das Nações Unidas para o Ambiente Humano, realizada em Estocolmo (Suécia) em 1972, foi aprovado uma Declaração em cujo primeiro princípio apresentou-se como direito inerente de todo ser humano dispor de um meio ambiente de qualidade e de proteger e melhorar o meio ambiente para as gerações atuais e futuras. Essa definição foi refinada nos relatórios "Estratégia de Conservação Mundial" de 1980 e "Nosso Futuro Comum" de 1987, também conhecido como Relatório Brundtland, e finalmente na Conferência das Nações Unidas para Desenvolvimento e Meio Ambiente de 1992 realizada no Rio de Janeiro, Brasil (BARBIERI; SILVA, 2011).

De uma maneira mais genérica, tomando por base o Relatório Brundtland, o Desenvolvimento Sustentável foi definido como "o desenvolvimento que atende as necessidades atuais sem comprometer a habilidade das futuras gerações de atender suas próprias necessidades" (NAÇÕES UNIDAS, 1999). Desde a Conferência de Estocolmo deu-se especial atenção à Educação Ambiental como um meio para se atingir o Desenvolvimento Sustentável (BARBIERI; SILVA, 2011).

Em 1975 foi realizado, sob os auspícios das Nações Unidas, o Seminário Internacional Sobre Educação Ambiental, em Belgrado (atual Sérvia, então lugoslávia), que resultou na chamada Carta de Belgrado, que definiu a meta básica, os objetivos e as diretrizes da Educação Ambiental. Esse Seminário foi seguido pela Conferência Intergovernamental sobre Educação Ambiental de 1977 realizada em Tbilisi (atual Geórgia, então parte da URSS), que ratificou os principais pontos da carta de Belgrado e refinou-os com um conjunto de recomendações (BARBIERI; SILVA, 2011).

A Conferência do Rio de Janeiro de 1992 produziu um documento, a Agenda 21, onde a Educação Ambiental aparece em todas as áreas, tendo inclusive um capítulo (o 36) exclusivo para ela. Durante este evento, ocorreu o fórum das Organizações Não-Governamentais (ONGs) no qual se publicou o Tratado de Educação Ambiental para Sociedades Sustentáveis (TEASS), onde a Educação Ambiental é visto como um processo de aprendizado permanente, baseado no respeito a todas as formas de vida e que contribua para a 
formação de uma sociedade justa e ecologicamente equilibrada (BARBIERI; SILVA, 2011).

No Brasil, em 1999 é instituída a Política Nacional de Educação Ambiental (PNEA) por meio da Lei 9.795, que define a Educação Ambiental como "os processos por meio dos quais o indivíduo e a coletividade constroem valores sociais, conhecimentos, habilidades, atitudes e competências voltadas para a conservação do meio ambiente, bem de uso comum do povo, essencial à sadia qualidade de vida e sustentabilidade" (BRASIL, 1999).

Detalhar os objetivos, princípios e ações da Lei 9.795, assim como os resultados das conferencias de Belgrado ou Tbilisi, ou da TEASS, é algo muito longo e que pode escapar do escopo deste artigo. Vale salientar que, a partir destes documentos, entende-se que a Educação Ambiental deve, entre outros (BARBIERI E SILVA, 2011; BRASIL, 1999):

a)Ser parte integrante de toda a sociedade e do dia-a-dia do cidadão, das empresas, do governo;

b)Balizar as decisões das políticas de desenvolvimento, visando a sustentabilidade;

c) Ter base na ética e no respeito às características culturais e regionais;

d) Criar consciência, conhecimentos, valores e ações por parte da sociedade;

e)Ser parte integrante dos currículos das disciplinas do ensino formal, do fundamental até o superior, não devendo ser uma disciplina em separado.

O PNEA define que as atividades de Educação Ambiental, aplicadas tanto no ensino escolar, em outras atividades de aprendizado e mesmo forma do ambiente escolar, devem (BARBIERI E SILVA, 2011):

a) Capacitar recursos humanos para a promoção e acompanhamento das atividades de Educação Ambiental;

b) Desenvolver estudos, pesquisas e experimentos;

c) Produzir e divulgar material educativo;

d) Acompanhamento e avaliação das atividades educativas e do aprendizado

Essa parte das atividades é que serão focadas no presente artigo, que propõe um conjunto de atividades que possam ser apresentadas tanto em ambiente escolar quanto fora dela (exposições, semanas temáticas etc.) e que estejam centralizadas na conscientização, controle e solução do problema de e-lixo. 


\section{Lixo eletrônico e a Educação Ambiental}

Como exposto anteriormente, o volume de lixo eletrônico produzido por ano tende a crescer em escala mundial. Este problema é agravado pelo fato de que muitos produtos eletrônicos se tornam obsoletos rapidamente, e seu descarte no ambiente ou reciclagem inadequada são riscos ambientais, principalmente devido a poluição por metais pesados ou produtos sintéticos (BALDÉ et al., 2015, 2017).

Para lidar com este problema, as alternativas disponíveis podem ser agrupadas nas seguintes linhas de ação (BALDÉ et al., 2015,2017; FERREIRA; FERREIRA, 2008, FREITAS, 2011):

a)Reaproveitamento das peças em bom estado e fabricação de máquinas funcionais a partir das mesmas;

b)Reaproveitamento das peças para outros fins;

c) Reciclagem das peças para aproveitamento de matérias-primas, especialmente metais preciosos;

d)Destinação final ambientalmente adequada às partes inservíveis ou não recicláveis em aterros sanitários.

e)Logística reversa, que é o retorno do equipamento inservível para o fabricante, para que este dê a destinação final adequada, e economia circular, que é o conceito do uso e reaproveitamento de insumos para um dado produto, em que o material descartado é novamente aproveitado para fabricação do mesmo insumo ou de versões mais novas deste insumo (ELLEN MACARTHUR FOUNDATION, 2017). listadas:

As vantagens destes tipos de procedimento são muitas, podendo ser

a) Redução da emissão de produtos tóxicos para o ambiente, reduzindo assim os riscos e impactos ambientais no solo, água e ar;

b) Produção de máquinas funcionais e de baixo custo que podem ser oferecidas e/ou vendidas a pessoas, comunidades, empresas, etc.;

c) Inclusão social, por ser uma fonte potencial de renda para comunidades de baixa renda que dependem da coleta e/ou separação do lixo como meio de vida;

d) Inclusão digital para pessoas ou comunidades de baixa renda, por disponibilizar máquinas gratuitamente para cursos de inclusão digital;

e) Potencial econômico nas matérias-primas obtidas a partir da reciclagem do lixo eletrônico. Baldé et al. (2017) calcula que o potencial valor econômico nas matérias-primas pode chegar a soma de 55 bilhões de euros (valores de 2016). Como citado anteriormente, essas matériasprimas podem novamente ser utilizadas na fabricação de novos aparelhos eletrônicos, dentro do conceito de economia circular (ELLEN MACARTHUR FOUNDATION, 2017). 
Portanto, o controle no descarte do lixo eletrônico representa um conjunto de ações diretamente relacionadas com a sustentabilidade, pois garantem a manutenção da qualidade ambiental, da disponibilidade de matérias-primas e promovem justiça social e inclusão digital.

Entretanto, para que tais ações sejam possíveis, ou mesmo parte da rotina do cidadão comum, torna-se necessário que o problema (lixo eletrônico) e a solução (ou controle) sejam do conhecimento da sociedade e que a mesma seja conscientizada sobre suas consequências e quais são as ações que se fazem necessárias. Em parte, isso pode ser alcançado com um arcabouço legal, que no caso Brasileiro é a Lei da Política Nacional de Resíduos Sólidos, que é a lei 12.305 de 2 de agosto de 2010 (BRASIL, 2010).

A outra forma é através da Educação Ambiental. Os parágrafos a seguir consideram os objetivos da Educação Ambiental, dispostos na Lei 9.795, no seu Artigo 5으, Capítulo I (BRASIL, 1999), que por sua vez são baseadas nas ideias das Conferências de Belgrado ou Tbilisi (BARBIERI; SILVA, 2011).

Os parágrafos I ("o desenvolvimento de uma compreensão integrada do meio ambiente em suas múltiplas e complexas relações, envolvendo aspectos ecológicos, psicológicos, legais, políticos, sociais, econômicos, científicos, culturais e éticos"), II ("a garantia de democratização das informações ambientais") e III ("estímulo e o fortalecimento de uma consciência crítica sobre a problemática ambiental e social") são parágrafos voltados principalmente a conscientização e informação.

Neste caso, a Educação Ambiental deve conscientizar a pessoa de que o lixo eletrônico é parte de um todo maior que envolve os impactos ambientais necessários a sua produção e ao seu descarte inadequado, ao consumo desenfreado e sem critério de bens eletroeletrônicos, aos problemas sociais associados seja à extração da matéria-prima, a produção, ao descarte e reciclagem inadequados.

O parágrafo IV ("o incentivo à participação individual e coletiva, permanente e responsável, na preservação do equilíbrio do meio ambiente, entendendo-se a defesa da qualidade ambiental como um valor inseparável do exercício da cidadania") envolve a ideia de ação, quanto à participação na defesa da qualidade ambiental, o que é por sua vez um princípio da sustentabilidade. Neste caso, há o conjunto de ações visando a minimização dos impactos causados pelo lixo eletrônico, como por exemplo a separação deste para reciclagem e disposição final adequada, retorno do equipamento descartado a empresas, grupos, pessoas que promovam a logística reversa e a economia circular, e preferência a empresas que promovam tais ações.

$\mathrm{O}$ parágrafo $\mathrm{VI}$ ("o fomento e o fortalecimento da integração com a ciência e a tecnologia") é um ponto importante, pois é a promoção dos conhecimentos e técnicas para os processos (reciclagem, reaproveitamento) destinados a dar a destinação final e sustentável do lixo eletrônico, como também na produção de material de material de ensino sobre o lixo eletrônico 
visando justamente a promover a conscientização do indivíduo e da coletividade da apresentação do problema em si como das alternativas de seu controle (dispostos nos parágrafos I a IV).

Logo, com o material disponibilizado sobre o lixo eletrônico, cria-se um material que pode ser apresentado tanto para o ensino formal nas instituições de ensino fundamental, médio ou superior como também em exposições, eventos e similares abertos ao público, em um ambiente fora do ensino formal, e permitindo o acesso aberto e irrestrito a todos.

Esta dimensão está de acordo com o Artigo terceiro do capítulo I da lei 9.795/99, com o Artigo quarto da mesma lei (dos Princípios da Educação Ambiental), especialmente no que se trata dos aspectos holísticos e integradores da Educação Ambiental, integrando maio ambiente e sociedade (BRASIL, 1999). O lixo eletrônico pode também ser incluído como material de estudo na formação de recursos humanos, especialmente de professores (Artigo 8, Parágrafo I).

A produção de material sobre lixo eletrônico para o ensino formal e não-formal pode ser individualizado no capítulo II (da Política Nacional de Educação Ambiental) parágrafos II e III, que dispõem sobre "desenvolvimento de estudos, pesquisas e experimentações" e "produção e divulgação de material educativo".

Nos Artigos 10 e 11 do mesmo capítulo tratam da Educação Ambiental no Ensino formal, indicando que a dimensão ambiental deve constar do currículo das disciplinas. Isso implica que a problemática do lixo eletrônico deve necessariamente transcender a uma disciplina, mas deve ser exposta em várias disciplinas. Neste caso, e em especial para o ensino médio, o lixo eletrônico pode ser exposto dentro desta perspectiva multidisciplinar nas seguintes disciplinas:

a) Matemática, na quantificação de materiais e insumos;

b) Física, por envolver eletricidade;

c) Química, pela composição química do lixo, e dos materiais tóxicos;

d) Biologia, pelos efeitos nos seres vivos que os componentes tóxicos podem causar;

e) Organização Social e Política Brasileira (ou disciplinas similares), sobre as leis existentes que dispõem sobre o lixo eletrônico, como a lei da Política Nacional dos Resíduos Sólidos.

O Artigo 13 trata da Educação Ambiental Não-Formal, o que implica "as ações e práticas educativas voltadas à sensibilização da coletividade sobre as questões ambientais e à sua organização e participação na defesa da qualidade do meio ambiente" (BRASIL, 1999). O lixo eletrônico, sendo um problema crescente e impulsionado pelo consumo e descarte cada vez maior de produtos eletrônicos, é indubitavelmente um problema que exige conscienti- 
zação por parte da sociedade para que dela partam ações que auxiliem a mitigar ou controlar as consequências mais nefastas deste problema.

\section{Proposta de atividades de Educação Ambiental com o lixo eletrônico}

A partir do que foi exposto anteriormente, sob a luz das normas da Lei 9795/99, pode-se então apresentar uma proposta para a inclusão do tema "lixo eletrônico" nas atividades de ensino formal e não formal.

Essa atividade proposta tem como objetivo:

a) Apresentar e explicar o que é lixo eletrônico, através de um ou mais exemplos;

b) Expor exemplos do conteúdo e dos riscos ambientais apresentados;

c) Expor exemplos de procedimentos destinados a correta disposição final, no caso, reuso, reciclagem e outros.

d) A partir da apresentação do que é o lixo eletrônico, seus riscos e soluções, propor ações de conscientização do lixo eletrônico no próprio meio em que vive o/a aluno/a, e das ações a serem tomadas em caso de descarte.

Esta proposta tem como base as atividades de pesquisa desenvolvidas pelos seguintes projetos:

a) Projeto "e-lixo Universitário - Oficina Prática e Inclusão Digital", sendo este um projeto de extensão dos Cursos Superiores de Tecnologia da Universidade Católica de Brasília (UCB), no período 2009-2014;

b) Projeto"e-Lixo: Reiniciar Tecnologia Sustentável". Este projeto de pesquisa foi aprovado dentro do Edital 03/2015, Demanda Espontânea, da FAP/DF (Fundação de Amparo à Pesquisa do Distrito Federal), tendo suas atividades centralizadas na Universidade Católica de Brasília (UCB), com atividades de pesquisa realizadas em conjunto também na Universidade de Brasília (UnB), no Distrito Federal, e na Escola Superior de Agronomia Luiz de Queirós (ESALQ), em Piracicaba, estado de São Paulo. O período de atividades deste projeto foi entre os anos de 2015 a 2017.

A apresentação do lixo eletrônico deve constar de uma parte gráfica, seja na forma de painéis impressos ou projetados com projetores disponíveis (especialmente do tipo datashow). Essas informações devem ser:

a) As definições do lixo eletrônico;

b) O volume produzido no Brasil e no mundo, mostrando o crescimento do volume produzido;

c) Exemplos de materiais existentes no lixo eletrônico que podem impactar negativamente no meio ambiente. 
Junto com esta apresentação, deve-se montar uma bancada ou mesa onde se expõe um ou mais exemplos de lixo eletrônico, tanto montados como desmontados. Recomenda-se 0 isso de computadores tipo desktop e periféricos, e de telefones celulares descartados, que são de acesso ou disponibilidade mais simples. No caso de equipamentos desmontados, pode-se colocar as peças em separado e classificadas pela sua função, assim como indicar os elementos químicos associados a cada uma destas peças (Figuras 1 e 2).

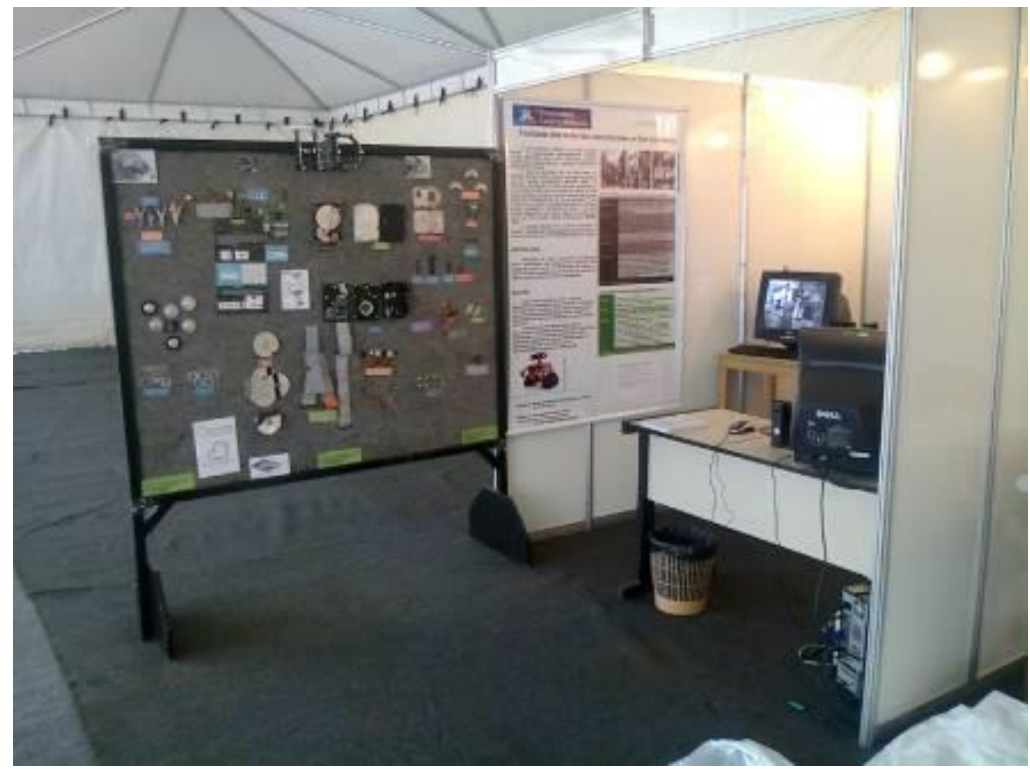

Figura 1: Exposição dos projetos de extensão de 2012 na Universidade Católica de Brasília (DF). No centro, painéis com texto sobre o lixo eletrônico e mostrando peças de computadores como exemplos de componentes do lixo eletrônico. Fonte: Foto dos autores.

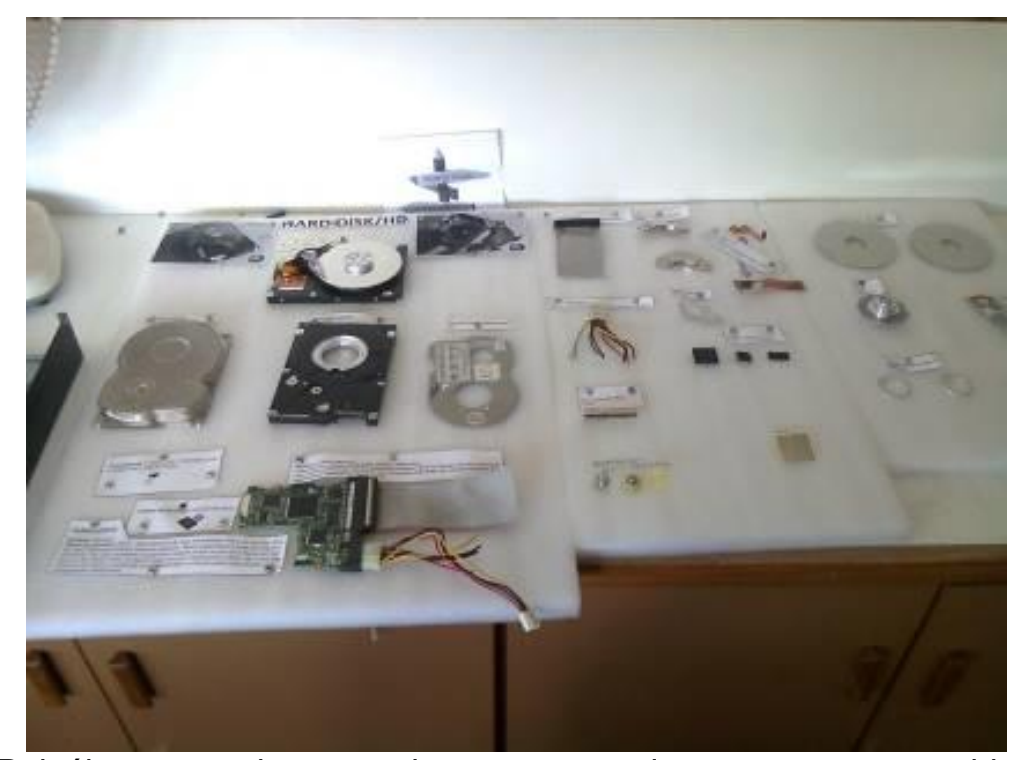

Figura 2: Painéis mostrando partes de um computador, com as mesmas identificadas e acompanhadas de texto explicativo indicando a função e os componentes químicos nelas existentes. Fonte: Foto dos autores. 
Deve-se chamar a atenção para o fato de que nesta parte também deve ser alertado sobre os riscos do lixo eletrônico mostrando, nos mesmos painéis, os riscos que determinados elementos presentes no lixo eletrônico podem fazer na natureza e com a saúde humana. Neste ponto pode ser dada ênfase nos chamados metais pesados, especialmente cobre, chumbo, zinco e mercúrio, presentes nos componentes do lixo eletrônico.

Peças isoladas e que não apresentem riscos podem também, caso possível, ser apresentadas para que os alunos/as possam examinar de perto tais componentes. Placas de memória, CPUs, resfriadores de alumínio são exemplos de peças que podem ser apresentadas para que os alunos/as possam examinar o lixo eletrônico de perto.

Um aspecto interessante é que em peças como CPUs e placas (ou "pentes") de memória contém ouro, identificadas pela cor dourada existentes nas mesmas. Esse detalhe pode e deve ser ressaltado na apresentação, pois ela é importante para a parte a seguir, que é a da reciclagem.

A reciclagem do lixo eletrônico para a extração de matérias primas deve ressaltar que este procedimento:

a) Reduz a necessidade de se extrair por meio de atividades como a mineração, que causam impactos ambientais;

b) Reduz o volume do lixo eletrônico nos aterros;

c) Reduz a quantidade de metais pesados que podem estar expostos e que podem causar contaminação ambiental e doenças ao ser humano.

Um procedimento de reciclagem utilizado com frequência para a reciclagem do lixo eletrônico é a chamada hidrometalurgia (ZHANG; KRUMDICK, 2011), que é um processo que envolve o uso de ácidos, e que está descrito mais adiante. Neste caso, deve ser explicado que o ouro é um metal muito resistente a ácidos. Assim, a peça contendo ouro deve ser colocada em um frasco com ácido, onde este ácido dissolve todos os metais, exceto o ouro. $\mathrm{O}$ ácido fica com uma coloração azulada e as peças com ouro ficam separadas.

Neste caso é claro que uma exposição não pode nem deve apresentar um frasco contendo ácido, devido aos riscos que ela apresenta, como derramamento acidental, ou mesmo riscos de respingos. Neste caso, pode-se utilizar uma simulação ou cópia. Recomenda-se usar um béquer pequeno com água colorizada por corante, preferencialmente corante não-tóxico, de cor azul, pois é esta cor que o ácido fica ao dissolver metais existentes no lixo eletrônico. Dentro do frasco com a simulação do ácido, pinos de CPU e partes cortadas de placas podem ser colocadas, servindo assim como um simulacro de um evento prático ou real.

É essencial que se enfatize aos alunos que a atividade de reciclagem deve ser feita em ambientes com segurança por envolver materiais corrosivos 
ou perigosos, não devendo ser feito em ambiente caseiro. Este ponto é importante para deixar claro que o processo de reciclagem é potencialmente perigoso e tóxico. É transmitir a mensagem do "não tente fazer isso em casa".

Os/as alunos/as devem ser informados/as que os diversos metais podem ser separados com o uso de ácidos. Assim, as peças de lixo eletrônico são colocadas em banhos ou frascos com ácidos onde o ácido dissolve e leva alguns metais (como o cobre), enquanto outros metais (especialmente o ouro e a prata) não são dissolvidos. Esses metais que não são atacados são separados e depois refinados ou derretidos para seu aproveitamento. $\mathrm{O}$ ácido, por sua vez, pode ser tratado quimicamente para aproveitar os metais que dissolveu.

As Figuras seguir mostram um exemplo real de experimentos dos projetos realizados na UCB sobre reciclagem de lixo eletrônico (Figuras 3 e 4) (FRANCO, 2015; SANTANA, 2016).

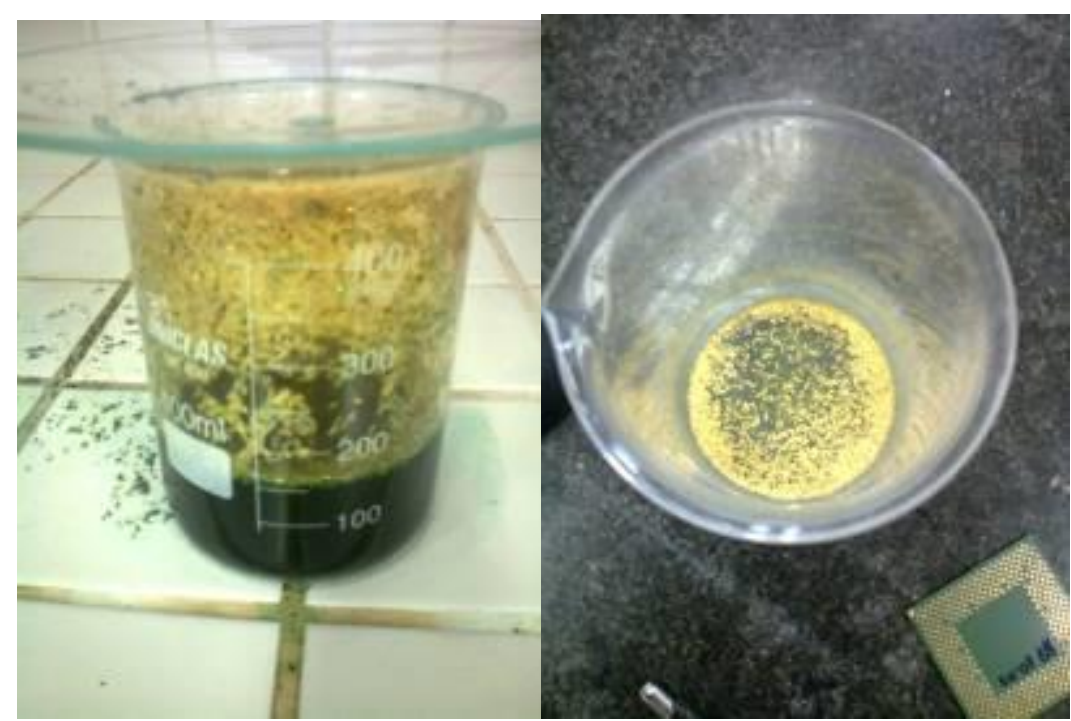

Figura 3 (esquerda): Frasco contendo ácido e pinos de CPU. O ácido está azul após dissolver todos os metais, exceto o ouro nos pinos. Figura 4 (direita): frasco após a retirada do ácido, mostrando as folhas de ouro correspondentes aos pinos onde todos os metais foram dissolvidos, exceto o próprio ouro. Observe a CPU sem pinos ao lado do frasco. Fonte: Fotos dos autores.

O processo de reciclagem pode ser apresentado de forma simplificada aos estudantes por meio de um fluxograma:

Separação dos componentes $\rightarrow$ derretimento ou ataque ácido $\rightarrow$ tratamento dos metais obtidos.

Por fim, há o chamado reuso do lixo eletrônico, que consiste, entre outras finalidades, dar novos usos ao lixo eletrônico ou reaproveitar suas peças para a fabricação de equipamentos operacionais. No último caso, 
computadores tipo desktop podem ser montados por técnicos ou fotografias deste tipo de equipamento apresentadas (Figura 5).

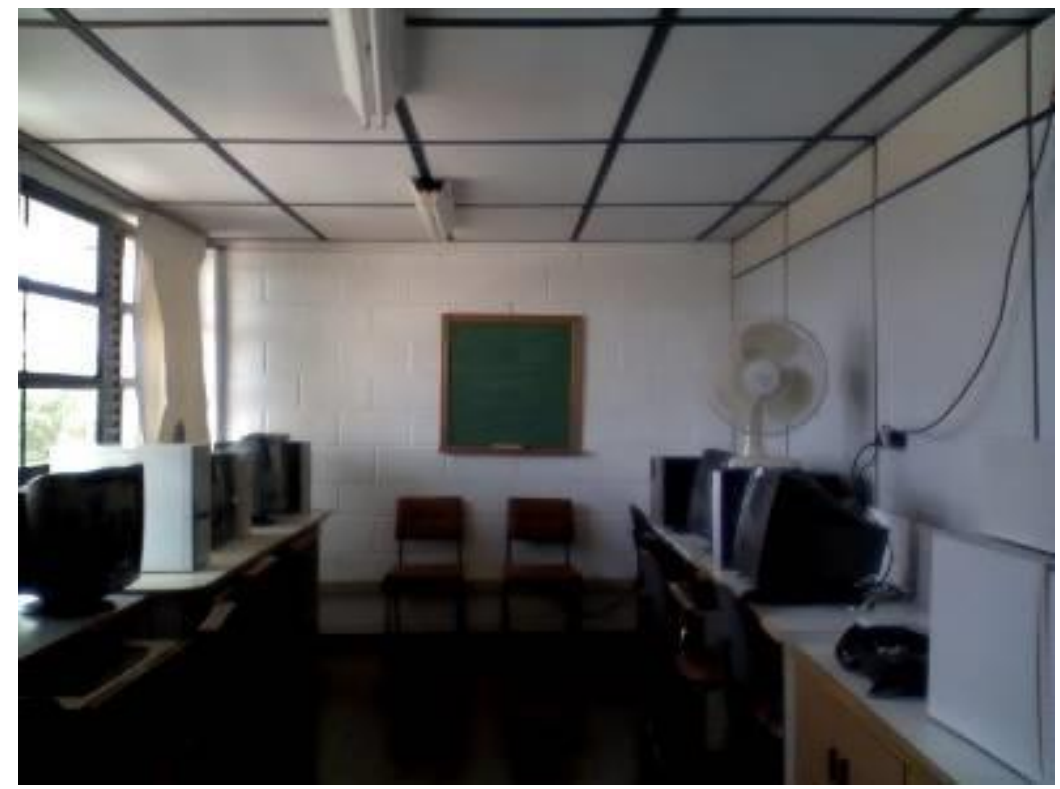

Figura 5: Sala para Inclusão Digital do projeto de Alfabetização Cidadã, projeto de extensão da Universidade Católica de Brasília (DF), mostrando computadores operacionais montados a partir de lixo eletrônico. Fonte: Foto dos autores.

Um aspecto lúdico que pode ser explorado do lixo eletrônico é a possibilidade de se produzir artesanato a partir do lixo eletrônico. Nesse caso, recomendam-se alguns cuidados, como verificar se o equipamento ou peça usada para o artesanato não apresenta nenhum risco tóxico ou peças pequenas que possam se soltar, entre outros. Produtos como chaveiros, vasos, porta-retratos, brinquedos etc. podem ser feitos a partir de lixo eletrônico, sendo mesmo encontrados em feiras de artesanato na atualidade.

A atividade referente à participação do próprio aluno/a pode ser feito tanto por um diálogo (atividade puramente verbal) ou por meio de uma ficha a ser preenchida pelo aluno/a ou por outra pessoa em caso de atividade em um ambiente fora do local de estudos. O tema da conversa ou artigo deve ser, é evidente, o lixo eletrônico, mas deve focar o mesmo no ambiente de vivência (casa, escola ou trabalho).

As perguntas podem variar de acordo com o docente, pois podem ter um viés mais aplicado a uma dada disciplina (matemática, química etc.). Porém, podem-se abordar alguns temas mais genéricos, como:

a) O estudante utiliza muitos produtos eletrônicos nas suas atividades diárias? Essa pergunta pode procurar enfatizar o uso de produtos eletrônicos mais populares em faixas de idade como a infância ou a adolescência, no caso microcomputadores, laptops, celulares de diversos tipos e videogames. 
b) O estudante descarta no lixo ("joga fora") os produtos que não são mais utilizáveis? Se sim, como é feito o descarte? Joga no lixo? Há algum tipo de coleta seletiva? Há pessoas que compram o material descartado? É doado (ainda que inoperante)?

c) O estudante já teve conhecimento sobre lixo eletrônico antes e dos problemas a ele associados?

d) O estudante aluno/a já viu muito lixo eletrônico ser descartado no ambiente em que vive (casa, escola, etc.)?

e) O estudante deseja descartar um produto que ele tenha (especialmente se ganha um celular novo, por exemplo) o que ele pode fazer para evitar algum tipo de problema?

A partir dos resultados deste questionário, o docente pode discutir com os/as alunos/as sobre como estes identificaram o lixo eletrônico no ambiente de casa, os riscos que podem trazer (em seu descarte inadequado), no conhecimento das alternativas possíveis e nas ações que podem ser realizadas para minimizar este problema.

\section{Conclusões}

A Educação Ambiental, conforme as definições feitas nos diversos eventos internacionais, como os de Belgrado, Tblisi e Rio de Janeiro, entre outros, e cristalizados no Brasil em norma jurídica pela Lei 9795 de 1999, é constituído por ações que devem ser aplicadas para toda a sociedade, dentro e fora do ambiente acadêmico/escolar, visando a conscientização e formação de novas atitudes, de recursos humanos e conhecimentos, com o objetivo de se alcançar a sustentabilidade e a qualidade ambiental.

Logo, tendo em vista que o Lixo Ambiental é um problema por ser o tipo de resíduo sólido cujo volume tem crescido aceleradamente nas últimas décadas, uma mudança de comportamento e paradigma torna-se necessária. Por exemplo, o aspecto da mudança de comportamento é relacionado com uma mudança do ponto de vista consumista dos produtos em um ponto de vista mais sustentável, com o reconhecimento dos problemas ambientais do descarte inadequado e da necessidade de um descarte adequado, envolvendo a reciclagem, a logística reversa (retorno para empresas produtoras do produto descartado) e reuso.

O conceito da economia circular é um conceito novo que vale a pena a ser introduzido nesta mudança por trazer a ideia de que um produto pode ser reciclado e fabricado várias vezes com o mínimo de exigência de matéria primas novas no ambiente. Essas mudanças podem ser alcançadas com a atividade de Educação Ambiental. Essa atividade pode ser aplicada tanto no ambiente de educação formal (escolas, universidades) como não-formal (empresas, eventos culturais etc.). A atividade consiste na apresentação dos dados sobre lixo eletrônico e do problema associado a ele. Essa parte emprega 
posters, vídeos e exposição de peças. Depois apresenta-se os métodos de disposição correta, com explicação sobre a logística reversa, economia circular, amostras de produtos feitos com peças descartadas, ou computadores funcionais feitos a partir de peças descartadas, e de procedimentos e produtos de reciclagem.

Este último exemplo (reciclagem) pode ser utilizado simulacros com materiais alternativos, porém inertes, para evitar riscos, uma vez que procedimentos de reciclagem podem utilizar processos ou materiais que são perigosos ou tóxicos.

Finalmente, a mudança de comportamento completa-se com questionários em que o estudante, cidadão ou outro é levado a perceber a presença do lixo eletrônico na sua rotina diária, e na conscientização dos riscos e das atitudes que deve tomar para minimizar, administrar ou resolver este problema.

Este processo de Educação Ambiental, diga-se ainda, está de acordo com o que é estipulado pela Lei da Política de Educação Ambiental, e mudanças na forma de sua aplicação podem ser realizadas pelos professores de acordo com as especificidades e características da região.

\section{Agradecimentos}

À Fundação de Apoio à Pesquisa do Distrito Federal (FAP-DF), pelo apoio financeiro à pesquisa desenvolvida pelos autores.

\section{Bibliografia Consultada}

ABRELPE - Associação Brasileira de Empresas de Limpeza Pública e Resíduos Especiais. Panorama dos Resíduos Sólidos no Brasil-2015. São Paulo, 2015.

BALDÉ, C.P.; WANG, F.; KUHER, R.E HUISMAN, J. The Global e-Waste monitor - 2014. United Nations University, IAS - SCYCLE, Bonn, Germany, 2015.

BALDÉ, C.P., FORTI V., GRAY, V., KUEHR, R., STEGMANN,P. : The Global e-Waste Monitor - 2017. United Nations University, International Telecommunication Union (ITU) \& International Solid Waste Association (ISWA), Bonn/Geneva/Vienna, 2017.

BARBIERI, J.C.; SILVA, D. Educação Ambiental na Formação do Administrador. São Paulo: Cengage Learning, 2011.

BISSCHOP, L. Is all going to waste? Illegal transports of e-Waste in a European transport hub. Crime Law and Social Change. 58(3), p. 221-249. 2012. 
BRASIL. Lei 12.305 de 2 de agosto de 2010, que institui a Política Nacional de Resíduos Sólidos. Presidência da República, Casa Civil, 2 de agosto de 2010.Disponível em: <http://www.planalto.gov.br/ccivil 03/ ato2007-2010/2010 llei/112305.htm > Acesso em julho de 2018.

BRASIL. Lei 9.795 de 27 de abril de 1999, que institui a Política Nacional de Educação Ambiental. Diário Oficial da União, Brasília, DF. 29 de abril de 1999. Disponível em: <http://www.mma.gov.br/port/conama/legiabre.cfm? codlegi=321 > Acesso em julho de 2018.

ELLEN MACARTHUR FOUNDATION. Economia circular. 2017. Disponível em <https://www.ellenmacarthurfoundation.org/pt/economia-circular-1/ conceito>. Acesso em junho de 2018.

FERREIRA, J.M.B.; FERREIRA, A.C. A sociedade da informação e o desafio da sucata eletrônica. Revista de Ciências Exatas e Tecnologia. Vol. III, Ano 3. São Paulo: Anhanguera Educacional, 2008.

FRANCO, M.N.S. Reciclagem do ouro de pinos de processador-CPU a partir de resíduo eletroeletrônico. Trabalho de Conclusão de Curso de Engenharia Ambiental, Universidade Católica de Brasília. Brasília, DF. 2015.

FREITAS, B.D. Logística Reversa: um estudo sobre a reciclagem de computadores. Trabalho de Conclusão de Curso de Administração da Universidade Católica de Brasília. Brasília, DF, 2011.

MOTA, S. Introdução a Engenharia Ambiental. 4ª Ed. Rio de Janeiro: ABES. 2006.

NAÇÕES UNIDAS. 42/187 - Report of the World Comission on Environmentand Development. United Nations Department of Economic and Social Affairs (DESA). 1999. Disponível em <http://www.un.org/ documents/ga/res/42/ares42-187.htm> Postado em 16 de dezembro de 1999. Acesso em julho de 2018.

SANTANA, A.L. Processo Químico de reciclagem do ouro e da prata oriundos de resíduos eletroeletrônicos. Trabalho de Conclusão de Curso de Engenharia Ambiental. Universidade Católica de Brasília. Brasília, DF. 2016.

ZHANG, L. E KRUMDICK, G. K. (Eds.). Recycling of electronic waste II Proceedings of the second symposium. The Minerals, Metals \& Materials Society / Wiley \& Sons, Canada, 2011. 